\title{
Trajectories of social vulnerability during the Soufrière Hills volcanic crisis
}

\author{
Anna Hicks ${ }^{1 *}$ and Roger Few ${ }^{2}$
}

\begin{abstract}
When some active volcanoes enter into an eruptive phase, they generate a succession of hazard events manifested over a multi-year period of time. Under such conditions of prolonged risk, understanding what makes a population vulnerable to volcanic threats is a complex and nuanced process, and must be analysed within the wider context of physical events, decisions, actions and inactions which may have accentuated the social differentiation of impacts. Further, we must acknowledge the temporal component of vulnerability, therefore our analyses must go beyond a transitory view to an understanding of the dynamics of vulnerability, particularly how inherent socio-economic conditions drive vulnerability today, and how patterns of vulnerability shift during the course of a long-lived crisis.
\end{abstract}

Keywords: Social vulnerability; Soufrière Hills Volcano; Montserrat; Dynamic; Impact; Livelihood

\section{Introduction}

The complex, variable and dynamic nature of volcanic activity creates a multi-dimensional impact on people and assets, influenced by physical and social vulnerability and societal capacity to respond. Attempts to reduce volcanic risk require a detailed understanding of how these components interact to change risk and impact resilience. The challenges for society - as well as for analysis - become accentuated further in situations where volcanoes enter into a prolonged eruptive phase, when the ramifications for society and economy can take on a deeper, more sustained nature.

Through the 'Strengthening Resilience in Volcanic Areas' (STREVA) project, a series of 'forensic' studies of risk were carried out in Montserrat, an island that has experienced a long-lived volcanic crisis since 1995. This paper focuses on dimensions of vulnerability analysed through the forensic research. In doing so, it takes a view of vulnerability that not only examines the antecedent conditions that could preclude or catalyse disasters, but also analyses the changes in capacity of a population to recover and adapt.

\footnotetext{
*Correspondence: a.hicks@uea.ac.uk

${ }^{1}$ School of Environmental Sciences, University of East Anglia, Norwich Research Park, Norwich, Norfolk NR4 7TJ, UK

Full list of author information is available at the end of the article
}

\section{Assessing vulnerability in volcanic settings}

In this study, we refer to 'vulnerability' as the potential to experience detrimental outcomes to wellbeing, lives and livelihoods, as a result of a hazard event - in this case a long-lived volcanic crisis. This usage of the term matches that within a body of critical social science work at the junction between political ecology, hazards research and development studies (e.g. Bankoff et al. 2004; Wisner et al. 2004; Cutter 1996; Schipper and Pelling 2006), which views vulnerability not just as a function of physical exposure to hazard but crucially also as a function of susceptibility to the effects of that exposure. Both components are inter-related and inherently 'social' in that it is social processes that largely determine different abilities to avoid, prepare for, withstand and recover from impacts of hazards (Wisner et al. 2004). This approach to analysing vulnerability therefore requires attention to social structures (such as modes of governance and rules of land tenure, for example) as well as to patterns of variance in resources and livelihood assets at the individual and household level (Pelling 2003; Few 2007; Gaillard 2008). Vulnerability is in this sense distinct from 'impact' (which is the actual effect of a hazard event), but the underlying idea we are proposing in this study is that in a post-eruption setting one can look at relative vulnerability as revealed through the prism of different impacts on different social groups.

\section{实 Springer}

(C) 2015 Hicks and Few; licensee Springer. This is an Open Access article distributed under the terms of the Creative Commons Attribution License (http://creativecommons.org/licenses/by/4.0), which permits unrestricted use, distribution, and reproduction in any medium, provided the original work is properly credited. 
Despite widespread recognition that assessments of vulnerability are essential to help design effective strategies for risk reduction to natural hazards, for volcanic risk, there remains disproportionate research focus on assessment of the hazard (Sword-Daniels 2011). Studies directed towards vulnerability assessment have a tendency to be focused solely on physical vulnerability (i.e. the likelihood of physical exposure to the hazard) and, while this is an important component of volcanic risk analysis, it needs to be supported by further research to identify the differentiation and dynamics of societal vulnerability to volcanic hazards (e.g., Dibben and Chester 1999; Wisner et al 2004). Further, empirical research that integrates vulnerability data into volcanic risk assessments is virtually absent (as an exception, see Hicks et al. 2014). This is likely a function of, a) the complexity of integrating qualitative and quantitative data sets; b) the challenges of effectively working in an interdisciplinary team to produce new knowledge, when disciplinary methodologies and epistemologies are seemingly incompatible, and c) a disciplinary mismatch of required time for data gathering (social scientific data, for example, usually requires a longer time to obtain than many forms of physical scientific data).
Forensic volcanic setting: Soufrière hills volcano, Montserrat

Montserrat is an active volcanic island within the Lesser Antilles volcanic arc (Figure 1). The Soufrière Hills volcano (SHV), located in the south of the Montserrat, became active in 1995 following a long period (estimated 400 years) of quiescence (Young et al. 1998). This prompted an evacuation of the islands' capital city, Plymouth (located $4 \mathrm{~km}$ from the volcano summit; Figure 2i), and several nearby towns and villages. Following another intense phase of volcanic activity in 1997, many displaced Montserratians accepted a migration package to the UK and elsewhere in the Caribbean. A population of over 10,500 was reduced to just 2,850 (the population has since risen to 4,922 [2011 census]). The last significant activity occurred in February 2010, and while this is the longest pause in activity since 1995, it is not yet clear that the eruption has finished and is officially still on-going (Scientific Advisory Committee on Montserrat 2013; Wadge et al. 2014b).

The political links with the United Kingdom (Montserrat is one of 14 British Overseas Territories) and the long-lived nature of the eruption has rendered the Soufrière Hills Volcano one of the most well-studied in history. As expected,

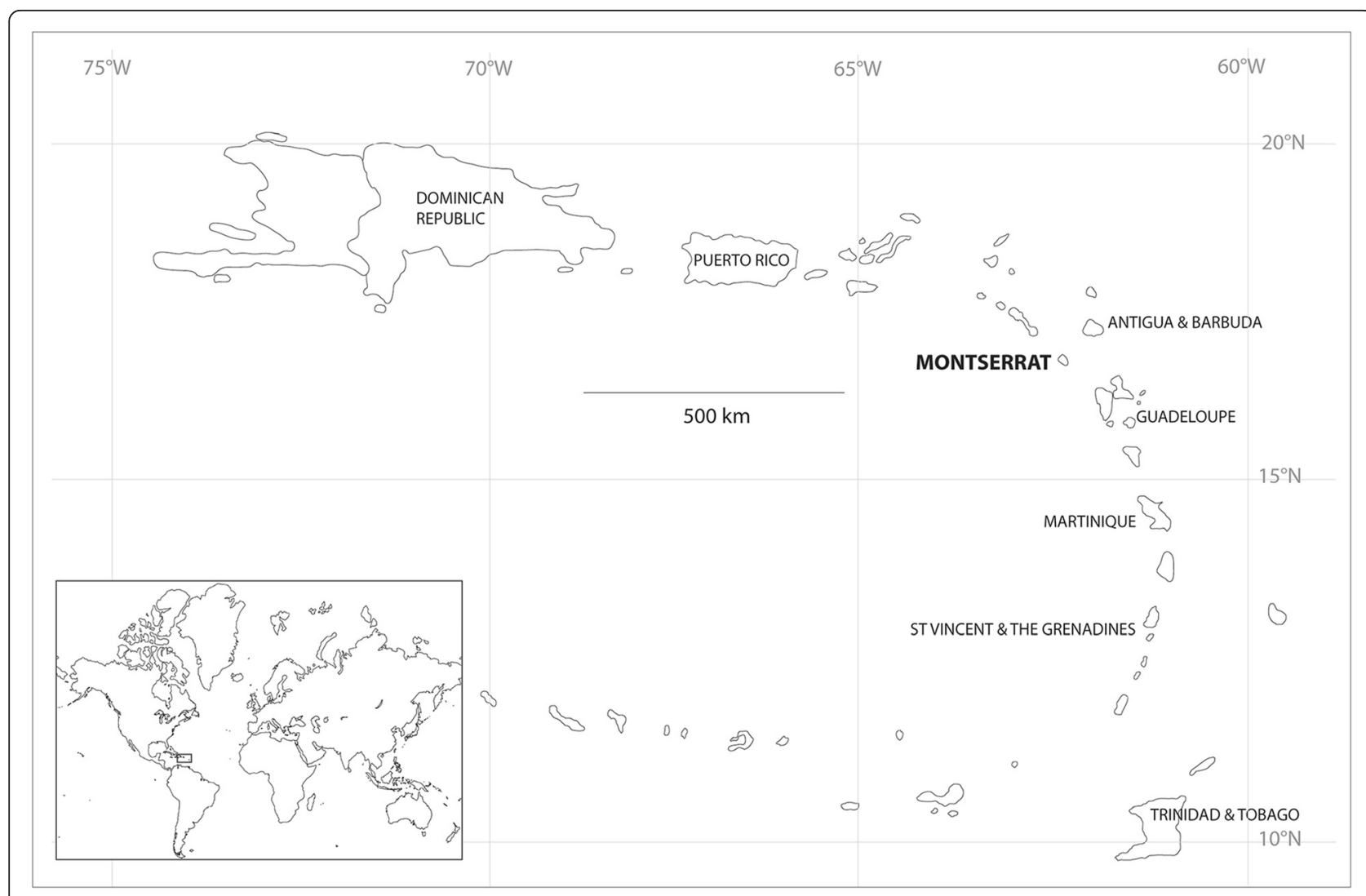

Figure 1 Sketch map of the Lesser Antilles, West Indies. Global position shown in the inset map. 


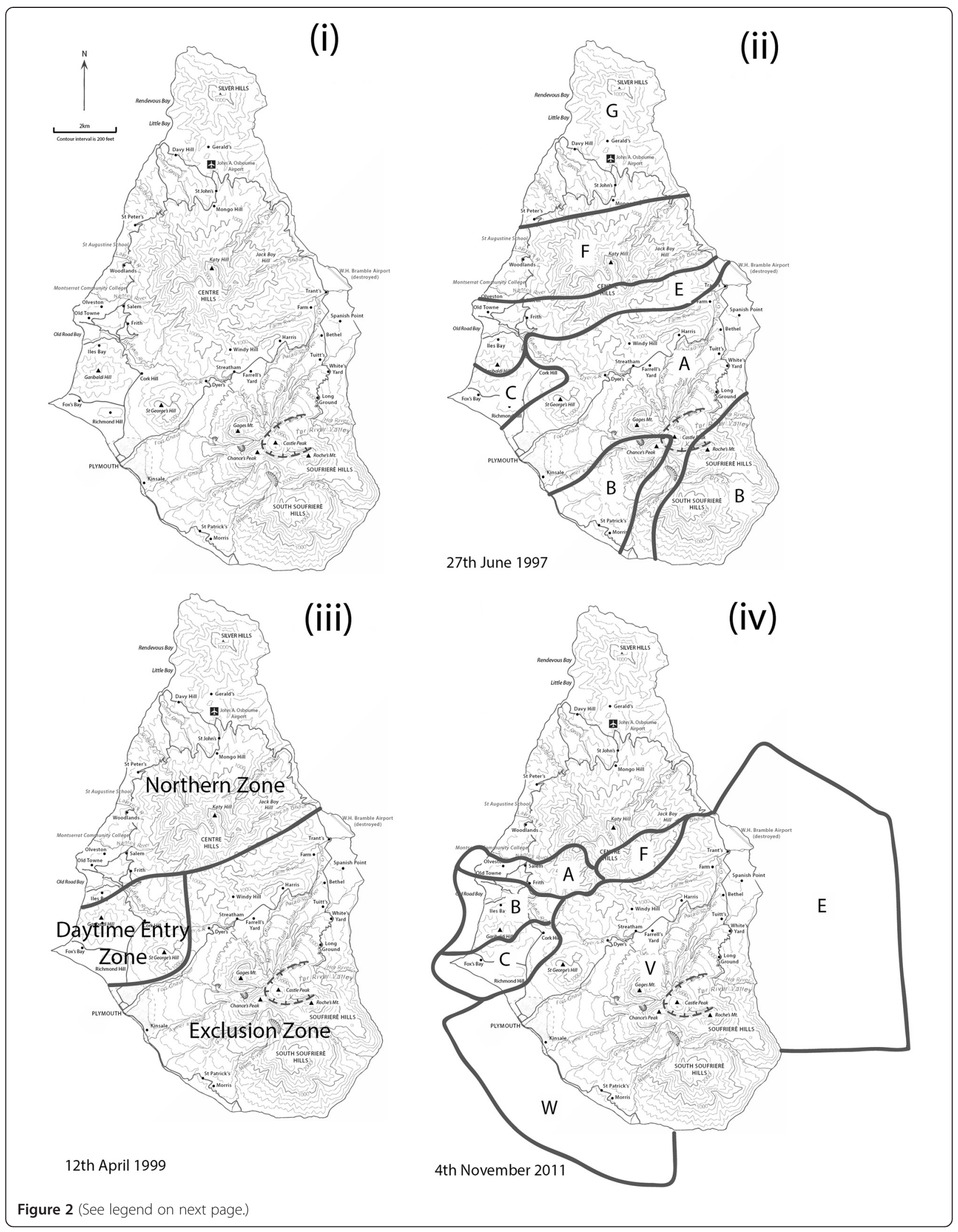


(See figure on previous page.)

Figure 2 Maps of Montserrat showing major towns and cities, exclusion zones and major revisions to them over time. Map (ii) is one of several revised maps showing the microzonation of Montserrat into seven hazard zones (A-G). Access to some of these zones, particularly $A$ and $B$, depended on the alert level ( 0 through to $5 ; 5$ being the highest alert level rendering zones $A-D$ inaccessible). Note that zone D was subsumed into zone $C$ following the events of June $25^{\text {th }}$. Map (iii) shows the three broad zones which replaced microzonation. Map (iv) was implemented in August 2008 in response to the new hazard level system http://www.mvo.ms/pub/Hazard_Level_System/. All maps have been redrawn from the original Montserrat Volcano Observatory maps.

the rich literature resource is dominated by studies of the volcanic activity of SHV and, to a lesser extent, general economic, social, emotional, health, cultural impacts of the eruptive phase on Montserratian people and society (Halcrow Group Limited and the Montserrat National Assessment Team 2012). However to date, there has been relatively little focus on the differentiation and dynamics of social vulnerability on Montserrat. This paper provides an analysis of vulnerable groups during the SHV crisis, and examines the processes of vulnerability generation.

We begin by describing our methodological approach to this study, framed around our 'forensic' approach. A description of the main volcanic phases of the SHV eruption follows, coupled with an account of some of the key social impacts during each phase. Finally we examine three of the most vulnerable groups that emerged from our analyses, followed by a discussion of social differentiation and dynamic vulnerability in volcanic settings.

\section{Methods}

The STREVA project's modus operandum is to undertake interdisciplinary, detailed exploration of long-lived volcanic crises to significantly improve knowledge of the ways in which the components and drivers of volcanic risk interact and can be characterised, analysed and monitored. These explorations of the causes, impacts and trajectories of volcanic crises are termed 'forensic investigations' (Burton 2010) and provide a platform for interdisciplinary teams to integrate systematic analyses of risk drivers, with a focus not just on the geophysical, but also on the wider societal drivers (e.g. governance, vulnerability, communication, infrastructure). The STREVA project focuses investigations around a forensic workshop, and combines this central data gathering activity with a series of key informant interviews and extensive study of a broad literature base. Each workshop is tailored for the particular context, but as a rule, they always include presentations, focus groups, and a field trip. The range of invited participants is also contextdependent, although crisis-response groups, government spokespersons and community representatives are always present. At each workshop, an event timeline is created by the workshop participants. This timeline records (on paper) physical and socially significant events before, during and after a volcanic crisis and provides a foundation upon which further multi-disciplinary data, gathered from other sources (i.e. interviews and literature), can be added and corroborated. Adopting a timeline-based approach provides a way of tracking events and impact pathways of the volcanic crisis on people and society, and illustrates responses and phases of change. In this paper, we present the results of this multi-phase data gathering approach, focused on analysing vulnerability during the SHV crisis.

The forensic investigation of the SHV crisis was centred around a two-day workshop, held in Montserrat, in September 2012. The aim of the workshop was to explore the extent to which Montserrat represents a resilient society by identifying the dynamic components and circumstances that have largely contributed to resilience, and those that have undermined it. Approximately 70 people attended the workshop, with scientists, government officials, disaster managers and community representatives in attendance. Involvement of the local community was a crucial component of the workshop, offering them an opportunity to have their voices heard, and to share individual and collective experiences and opinions. Workshops participants were carefully chosen to ensure that: a) numbers of scientists did not outweigh non-scientists; b) numbers of ex-patriates did not outweigh Montserratians; and c) most participants had been involved in, or had memory of, the SHV crisis.

The workshop was divided into two themes: the first was entitled, "what is resilience, where and when is it manifest on Montserrat and how is it controlled?" and the second was: "critical moments during $\mathrm{SHV}+17^{\mathrm{a}}$ : dynamic risk, resilience and its drivers". Both sessions included presentations and facilitated break-out discussions, although for the latter theme, these group conversations were purposely designed to separate the delegates into particular 'specialisms': a) monitoring and hazards; b) risk and disaster managers and communicators; c) civil society. Each break out group was facilitated by a STREVA researcher with experience of these 'specialist' groups. The second theme was extended further by way of a series of charrettes to allow specialist groups to divide and re-form as mixed stakeholder groups. The final afternoon of the workshop was open to the public and included a panel session with key responders during the crisis.

Each break out group was recorded and extensive notes were taken. These conversations provided a rich qualitative data set, which helped both to guide the choice of who to interview post-workshop and to inform the set of questions posed. Sixteen post-workshops interviews were conducted with members of the Montserratian population, government representatives, decision makers and the 
UK-based Montserratian community. These were almost always conducted in the office or home of the interviewee, lasted between 20-60 minutes, and were recorded and transcribed. Interviewees were chosen largely as result of 'knowledge gaps' identified from the workshop (e.g. returnees from the UK; immigrant population), or if they were representatives of vulnerable groups identified from the workshop conversations.

To analyse the vulnerability component of volcanic risk, the evidence gathered from the workshop and interviews, along with existing material (academic, grey and policy literature), were collated, triangulated ${ }^{\mathrm{b}}$ for validation and coded against a set of 14 impact and response themes. The themes of this outcome-based analysis ${ }^{\mathrm{c}}$ were selected for their consistency across the evidence base and included: ashfall; stress; evacuations; shelters; migration drivers; buffer zones; clean up; rebuilding services; and rebuilding livelihoods. A second phase of coding focused on vulnerable groups within these broad themes: original residents of the south; original residents of the north; shelter population (early in the crisis); shelter dependents (longerterm); relocatees to the north (home owners); relocatees to the north (renters); residents of buffer zones; migrants to the UK (non-assisted); migrants to the UK (assisted); migrants elsewhere; remittance receivers; returnees; and in-migrants. Again, these groups emerged from the data due to extent and regularity of references across the evidence base. We acknowledge that these are not uniform groups, but for some extended families which intersected several of these social groups, the combination of circumstances has exacerbated vulnerability and impaired recovery. Drawing on this outcome-based analysis, here we focus our narrative on three particularly vulnerable groups: shelter dependents (longer-term); relocatees to the north, and migrants to the UK (assisted).

While it is recognised that rapid team-based qualitative inquiry can have limitations, particularly insensitivity to the social context and susceptibility to bias (Chambers 1994), this was minimized in this case by: 1 ) encouraging a strategic mix of people to participate in the workshop (i.e. a combination of scientists and risk managers with detailed technical knowledge and experience of the SHV, and knowledgeable and representative local residents with direct experience of the crisis' longer-term impacts); 2) analysing group discussions to identify vulnerable groups, identify key informants and inform the design of subsequent semistructured interviews; and 3) undertaking a series of subsequent in-depth interviews to deepen and substantiate the content of workshop discussions.

Before presenting results of our analyses, the following section briefly summarises the SHV crisis, the short term response, and its impact on the Montserratian population. While there have been five phases of volcanic activity since the crisis began, we have focused on the phases
$1-3$. The volcanological literature on the crisis is incredibly rich, and more comprehensive descriptions of events can be found elsewhere (e.g., Wadge et al. 2014a, b; Kokelaar 2002; Loughlin et al. 2002; Clay et al. 1999).

\section{The Soufrière hills volcanic crisis: overview of impacts and response \\ Phase one}

On the $18^{\text {th }}$ July 1995 , volcanic activity of Soufrière Hills resumed after a long period of dormancy. The first large eruption occurred on the $21^{\text {st }}$ August, known as 'Ash Monday', resulting in the evacuation of $\sim 6000$ people from Plymouth and nearby towns into temporary shelters (churches and schools). Evacuees reoccupied their properties two weeks afterwards, but volcanic activity temporarily forced them out again in December. On the $3^{\text {rd }}$ April 1996, Plymouth was evacuated for the final time, and a state of public emergency was declared. Over 7,000 people had to be relocated, and 1,366 people were housed in temporary public shelters. Living conditions were widely viewed as unpleasant; evacuees complained about overcrowding and lack of privacy, poor sanitation, and lack of access to good nutrition. A voluntary evacuation scheme was set up on the $23^{\text {rd }}$ April, offering Montserratians an opportunity to move to the United Kingdom, but only 1,244 people registered for this package. Several interviewees stated that this owed to hope that the eruption was short-lived. During this period, businesses began relocating to Brades, Salem and St John's, but towns in the North were struggling to hold any more evacuees, inducing further evacuations to the UK and elsewhere in the West Indies. In response to the atypical explosive-style of volcanism in September 1996, the island was 'microzoned' into seven hazard zones (A-G). The risk status of each zone was modified according to fluctuating alert levels, issued by the Government of Montserrat and based on recommendations from scientists at the MVO. Most areas in the north (zones G \& F) could be fully occupied even when the alert level was at its highest, and most areas in the south (zones A \& B) could not be accessed, or only accessed for short visits, when the volcanic dome was in a stable growth phase. All areas were accessible at the lowest alert level. Both the alert scheme and the maps were revised several times over the years (Figure 2), but these modifications resulted in some misunderstanding between the public, civil authorities and the scientists, and occasionally disregard to follow official warnings (Aspinall et al. 2002).

On the $25^{\text {th }}$ June 1997, a series of pyroclastic flows destroyed settlements and infrastructure (including the airport in the East) from Trants to Dyers and killed 19 people (Loughlin et al. 2002). Salem, Old Towne and Frith were evacuated in August 1997 (zone E; Figure 2), forcing towns in the north to accommodate a further 
1,300 people. Numbers in shelters rose from 775 to a peak of around 1,600 (Clay et al. 1999). On the $19^{\text {th }}$ August 1997, an assisted passage scheme was announced, which provided financial support for Montserratians to move to either the UK or a regional location. Over 4,000 people registered for the relocation package, and while some took advantage of pre-existing networks in the UK and moved in with friends and family (Shotte 2006; McLeman 2011), many were re-housed on estates in UK cities. On the $21^{\text {st }}$ May 1998, the UK offered a permanent settlement deal to evacuees from Montserrat. This had considerable impact on demographics; early in 1998, the population of Montserrat was only 2,850 - a $70 \%$ reduction from 10,625 (pre-eruption; 1991 census). On the $21^{\text {st }}$ May 1998, the UK offered a permanent settlement deal to evacuees from Montserrat.

The risk map was simplified in September 1997 (final revision in April 1999), and microzones were replaced by three broad zones: exclusion, central and northern (Figure 2iii). This map remained largely the same until August 2008 (final revision November 2011) when the new hazard level system was implemented, in conjunction with a new hazard zone map, dividing the southern two-thirds of Montserrat into five zones (A, B, C, F \& V) and two maritime exclusion zones (W \& E) (Figure 2iv).

After the intense phase of activity waned, Montserrat began to rebuild, following an injection of funds from the Department for International Development (DfID), along with the creation of a sustainable development plan $^{\mathrm{d}}$, and building of 'temporary' T-1_11 houses ${ }^{\mathrm{e}}$ in Davy Hill. This helped to reduce the numbers living in shelters to 427. In October 1998, the reoccupation of Salem, Old Towne and Frith began. Numbers of immigrants ${ }^{\mathrm{f}}$ began to rise to fill occupations left by evacuees. On the $1^{\text {st }}$ May 1999, an assisted return passage scheme began, and as the population gradually increased to $\sim 4,500$, growth on the island was stimulated and the construction industry was re-established. A new housing development was built at Lookout in the North, further reducing the shelter population to 372 .

\section{Phase two}

The volcano resumed dome growth in November 1999, beginning phase 2 (of 5 ) of the eruption. This was to be the longest phase of activity, pausing in July 2003. This phase was characterised by dome collapse events, sending pyroclastic flows down the Tar River Valley in the southeast (Figure 2). In October 2002 lahars affected the Lower Belham Valley area in the west (Figure 2). Residents were given 48 hours to evacuate. In the months that followed (296 days), residents were permitted to return to their homes in the exclusion zone between 09.00 and 14:00 (known as daytime entry), although access was withheld during periods of raised activity, due to the heightened risk of pyroclastic flows traveling down the valley. The Belham area was not permanently re-inhabited until after 13 July 2003 following a major dome collapse which greatly reduced risk to the Belham Valley.

\section{Phase three}

In August 2005, a new lava dome began to develop, but it was not until the $20^{\text {th }}$ May 2006 that explosions occurred, prefigured by the second largest dome collapse since the reactivation of SHV. Heavy ash falls affected most of the island, and required considerable investment from the Government of Montserrat to support further clean-up efforts. The necessity for extra manpower encouraged further immigration. The population according to the 2011 census was 4,922 .

\section{Sharpening the focus: the stories of the disadvantaged}

Results from the time-series analytical component of the forensic study are presented in Figure 3. Data used to inform this analysis was gathered from the forensic workshop, key informant interviews and available literature. Adopting a timeline-based approach provides a way of tracking events and impact pathways of the volcanic crisis on people and society, and illustrates responses and phases of change. While this impact timeline provides a useful illustration of the critical moments (and phases) in terms of social impacts on livelihoods and wellbeing to all Montserratians, vulnerability itself is a complex social characteristic and is more difficult to chart. While it can change, those changes are not necessarily sequenced by disaster events. However, the strength of impacts for different social groups can yield information on how vulnerability plays out, especially in the longer-term. Here we focus on trying to explain how particular social groups have proved to be more vulnerable than others, by analysing the impacts of the crisis on the 'worst affected' and the dynamics of that process. Essentially the timeline becomes a way to frame the vulnerability story of the disadvantaged, or those with the least capability to recover.

Our analysis of the workshop and key informant data indicates that those most disadvantaged by the lasting impacts of the volcanic crisis were/are: evacuees in long-term shelter accommodation; poorer non-migrants who resettled in the north of Montserrat and assisted passage migrants to the UK. Most workshop participants and key informants suggested that this was due to these groups being in a prolonged vulnerable state as compared to other the broad groupings which emerged from the second coding phase. Here we present results from the experience and perspectives of members of these groups, and those who liaised directly with them, along with an explanation of the antecedent conditions 


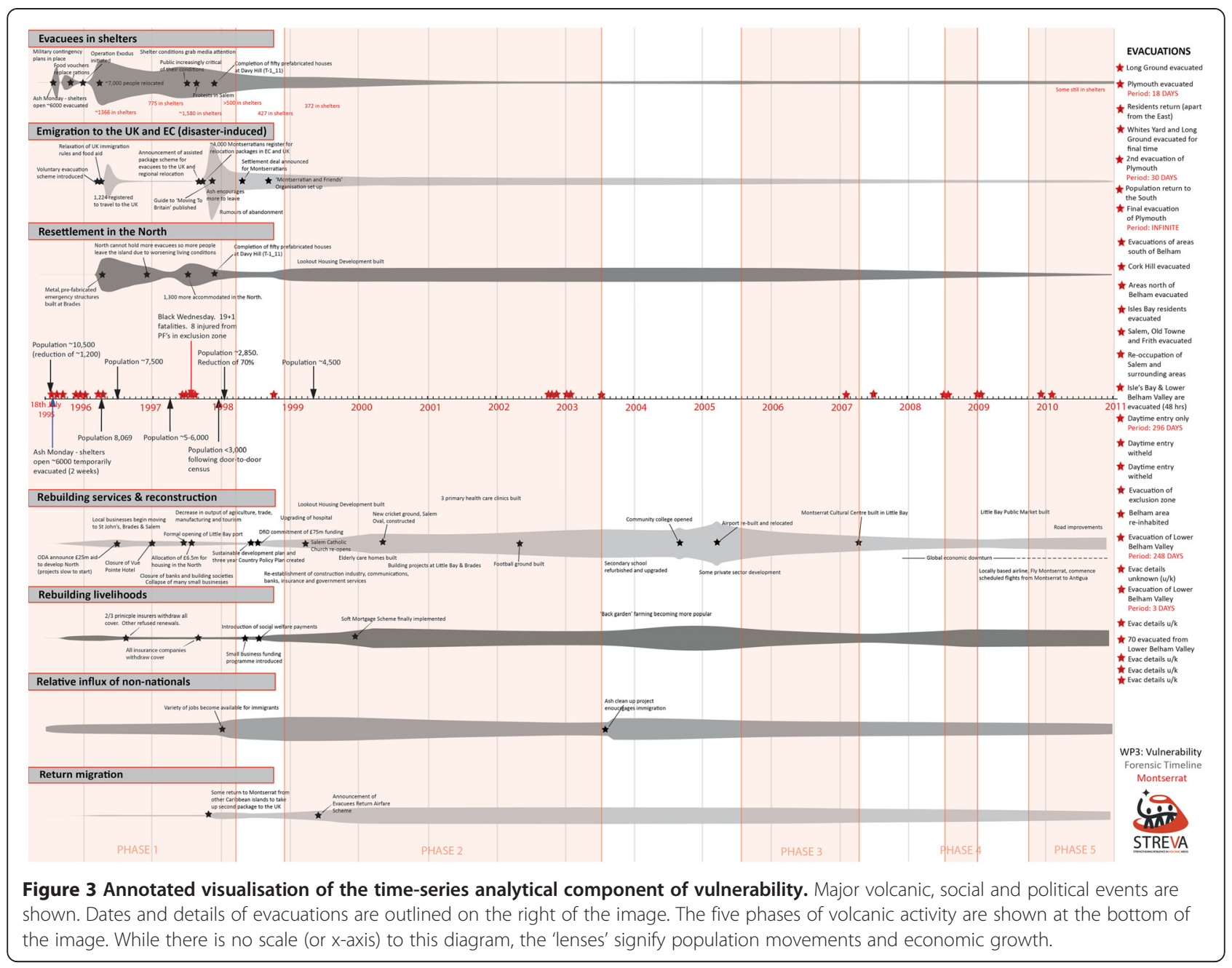

that led to a more vulnerable position, the consequences and the long term situation.

\section{Long-term shelter dependents}

Those evacuees who remained in temporary shelters were predominantly families and individuals with fewer livelihood assets. There were two broad sub-groups of people: 1) those with lack of access to alternative accommodation via social networks in the north or other countries, and/or the economic means to rent or build new accommodation; and 2) older people that were left behind by migrant families.

Following the first evacuations in 1995, schools and churches were made into emergency shelters. Many people were encouraged to share houses with friends and family (families in the north were given allowances to house other people with them), but the numbers requiring the use of public shelters was still large, so tents were erected in Gerald's Park in the north of Montserrat (Clay et al. 1999). In April 1996, metal prefabricated structures were erected in Brades, and timber chalets were erected for displaced people following the second evacuation of Plymouth. These could accommodate up to 20 people. Funding for emergency housing was not allocated until July 1997. As Clay et al (1999), p.34 report: "The public shelter programme was basically successful in providing everyone with immediate shelter, but was unsatisfactory in providing for more extended occupation." However, most shelter types were used for extended periods of time. For example, the metal shelters, which were reported to be unbearably hot to stay in during the day (Skelton 2003), were still occupied three years after the onset of the crisis (Pattullo 2000).

Several interviewees and focus groups reported that the consequences of shelter dependency included: exposure to health risks from poor sanitation, crowding and nutrition; risks to personal security; emotional stress/depression; and re-entry into to exclusion zones. In her account of the disaster, Pattullo (2000), p.91 describes the shelters as, "inadequate and often squalid". Personnel working at the Emergency Operations Centre (EOC), who were in charge of maintaining the shelters, found it particularly difficult to dispose of human waste: 
"The sanitation consisted of pit latrines less than 2 metres deep. They were intended to be in use for two days. They were, in fact, used for more than two years." (Pattullo 2000, p.94).

It is possible that this led to the increased levels of gastro-intestinal illness that was recorded during this period of the crisis. Many people were reliant on shelters, with up to 1,600 people (in August 1997) forced to tolerate crowded conditions, as the following quotes describe:

"Now at the shelter you could imagine 20 persons living in this room after coming from a private home, just coping with that, just the emotional thought of that." (EOC Employee)

..."we started in what we referred to as the rural areas, where you had the rural poor - you had a mixture of vulnerable groups, but clearly those were the ones who were impacted the most. Those are the ones that I saw in the shelters really suffer....Now a church is designed to have a two hour, at the most, celebration, and you return home. But when you convert that now to a place where folk are living, no partitions, and the restroom facilities were not designed for 60-100 people." (Community Services Employee)

The EOC were also in charge of food distribution, although provisions were mostly canned goods which were easier to disseminate. The quality of the food soon began to raise issues:

... "because a lot of them were accustomed to eating a lot of what they produced - so that food situation was desperate for these vulnerable groups [farmers]...Right away, the stress of the situation, plus the food, created health problems." (Community Services Employee).

..."we were seeing guys come in with foot and a half long carrots and we'd say hey, where was this grown and they'd say right up there [the exclusion zone]... the government agreed let us take some money and purchase some of the crops from them so that at least they could harvest and have some income and [for] the people in the shelter at least we could change the diet a little bit and make it a little easier..

(Community Services Employee).

Unfortunately this desire to help those in need, and to continue earning a living, encouraged some farmers to reenter the exclusion zone.

"People died because they wanted to get crops to feed people in the shelters - the aid wasn't enough and

\section{people wanted to help the EOC feed people."} (Government Official)

During the inquest ${ }^{\mathrm{g}}$ into the deaths of $25^{\text {th }}$ June 1997, the jury decided that the failure of British and Montserratian governments to provide land for displaced farmers had contributed to the nine of the nineteen deaths.

If the presence of standing crops was a pull factor, so it appears that the conditions of shelter life were a push factor to re-enter the exclusion zone. Several workshop participants commented that some of those who died had either refused to move to the shelters or had returned to spend time at their homes in the exclusion zone. Two interviewees spoke not only of the physical deprivations of the shelters but also of personal security issues such as incidences of aggression, power struggles, rape and sexual abuse:

"...and to end up in a hall with 60 or how many people, [at night] people were being touched, and they are not certain who touching me... when we started there were no partitions - eventually an effort was made to use plywood and stuff and at least create some semblance."

(Retired Community Services Employee)

There was some public disobedience fuelled by treatment in the shelters, and protests broke out (particularly in Salem). While this tension was ameliorated through the assisted passage scheme, conditions did not improve for those that stayed in shelters. As Clay et al. (1999, p.33) report, "The conditions and length of time that people have had to endure living in public shelters have been regarded as unacceptable in terms of British and industrial country standards of social well-being."

One of the unanticipated negative consequences of families abandoning Montserrat was that many left their elderly on the island. A shelter for the elderly opened initially as many of the aging population required care as well as accommodation, but the insanitary and crowded conditions in this particular shelter drove several of the occupants to return to their homes in the exclusion zone (Loughlin et al. 2002). There were reports of elderly becoming depressed and anxious (Avery 2003; Stair and Pottinger 2005), and in response, the government created three permanent residential homes.

There may have also been longer-term chronic health and mental health effects of extended shelter residence across the dependent population (Stair and Pottinger 2005; Hincks et al. 2006). While there is no concrete evidence for cause and effect, several focus groups claimed that poor diet (modest intake of fresh produce) and lack of exercise led to an increase in depression, hypertension, obesity and [symptoms of] diabetes. Today, almost 20 years after the onset of the crisis, there are still people 
occupying shelter accommodation (Sword-Daniels et al. 2014), although exact numbers are uncertain.

\section{Poorer non-migrants who resettled in the north}

Life for those outside the shelters was also challenging, especially for those struggling to establish homes and livelihoods following displacement from the south. As several focus groups participants and interviewees reported, many non-migrants who relocated to the north of Montserrat were initially reliant on the hospitality of family and friends or rented accommodation. This group included people who had never had substantial financial assets, but also home-owners from the south who were already paying mortgages for their abandoned homes (some people are still repaying loans on empty dwellings today). It was also due to shortage of available land:

\section{"Land in north was family land so [they] did not want to sell it and there were difficulties getting the agreement of family members.... this partly explains why the government did not do more in the north, because it could not buy the land." (Government Official)}

Further, the shortage of available land in the north meant that land prices rose sharply. While this had an effect on the Government of Montserrat, who needed to purchase agricultural land from private landowners to start building housing developments, soaring prices particularly affected farmers, who could not afford to purchase replacement land:

\section{..."land was at a premium here [in the north] because people wanted places to build houses, they wanted places to establish businesses...So the farmland started going at rates that were comparable to business leases." (Employee of the Department of Agriculture)}

This further marginalised this rural social group. The destruction of farmland in the south meant that farmers lost their land, crops and livestock, and faced severe challenges in re-establishing their livelihood in the north (Rozdilsky, 2001). Those that were able to rent land were faced with challenges of cultivating in unproductive, infertile soils on small plots, resulting in low yields. Consequently, few farmers could make a living solely from farming, so many had to obtain a second occupation such as fishing or construction (Halcrow Group and the Montserrat National Assessment Team 2012). Some farmers who were able to transfer livestock from the south either did not have land sizeable enough for pasture, or were not able to build enclosures, so livestock were often unconfined. This in turn threatened crops of arable farmers. According to one interviewee, there were also reportedly instances in which tenant farmers were exploited, with landowners demanding the return of rented land, only after the land had been cleared by the tenants and started producing crops.

Overall, the farming sector of Montserrat has not only diminished but changed in trade from export to selling on-island and subsistence farming. A representative of the Department of Agriculture estimated there are just 70 farmers currently on Montserrat today, though only around five are full-time farmers, and some no more than 'backyard gardeners'. The longer-term situation of farmers renting in the north has also seen the diversification of farming methods and crops, apparently driven by inmigration from other islands:

\section{...."we have a Haitian guy who is actually...renting some land and doing some serious farming, which I hope will inspire some of the other locals to get back in....The cuisine is changing because of people of different [cultures], and so in farming you have crops like pak choi.... Those kind of things you find people now planting that and selling that - some of the locals even planting some of these different crops" (Employee of the Department of Agriculture)}

However, as emphasised by one interviewee, others have not been keen to take risks in their approaches to farming, as they do not have security of tenure, and are aware of the threat of future ashfall and acid rain (Halcrow Group and the Montserrat National Assessment Team 2012). The risk of acid rain and heavy ashing was persistent throughout the post-evacuation period, when a change in wind direction would re-direct the sulphurous gas/ash plume over to the north, sometimes causing crops to disappear overnight.

Over time, new houses for relocatees were built in the north, but several interviewees raised concerns about the structural quality and location of some of this housing. One of the longer term effects of the land shortage in the north was that some new homes (even governmentfunded housing estates) were erected in unsafe and unsuitable locations such as ravines. One of the new housing developments, Lookout, comprised of 200 units, eventually enabled many renters to purchase their properties. However, some houses in the development were built in apparently poorly planned locations - on steep, exposed slopes that have limited shelter against hurricanes, earthquakes and windborne salt (Mitchell 2001; Smith Warner Report 2003). Another re-development in Little Bay is also at risk from regular coastal flooding (Mitchell 2001). Possibly due to the lack of available space on which to re-build and/or the time pressures of relocating shelter dependents, hazard mitigation did not play a central role in the initial rebuilding phase, thus further affecting the vulnerability of these affected groups. 


\section{Assisted passage migrants to the UK}

The motivation to register for the relocation package was a major subject of discussion in the workshop focus groups as well as in several of the key informant interviews. The balance of perspectives was that motivation for those evacuated from the south arose from a combination of necessity and opportunity. Strong drivers were the dependence on shelters and mortgage commitments of abandoned homes:

"One of the big failures at the beginning of the volcanic crisis was that the insurance companies all closed and they didn't pay people out.... a lot of people had mortgages...that's one of the reasons people left who otherwise would have stayed, because their paychecks were docked for the mortgage payments [on abandoned homes]" (Workshop participant

[Montserratian resident])

However, it was not only the relocatees from the south who registered for the package:

"The other thing we spotted was the some people in the north decided to move because they were just so overwhelmed by so many people coming into their environment. Some just locked their houses and took off." (Retired community services employee)

\section{... "More emigrated from the north as they mostly worked in agriculture and had no employment post- eruption, whereas people from the south were more likely to be in government jobs which were main- tained." (Workshop participant [Montserratian])}

This did have some positive consequences for the distribution of the remaining population:

"The fortunate thing is that...for some of us, is that some of the people from the north, who did not necessarily have to migrate, wanted the chance to go to the UK, so that migrated and they created space for some of us [people from the south]" (Employee Department of Agriculture)

Many reported on bring fearful of the eruption and the potential for larger, on-going activity. Reports on health issues during the eruption also underlined that migrants were motivated by health concerns from inhaling ash and from the poor hygiene in the shelters, particularly for children (Avery 2003; Forbes et al. 2003; Howe 2003). A study by Forbes et al (2003), conducted in 1998, reported that, "children who lived in areas with moderate or heavy exposure to ash since July 1995 reported more respiratory symptoms and use of health services for respiratory problems than children who had never lived in these areas" (p.209). Further, she reports, "asthma was frequently cited as a medical condition among families who left under the Assisted Passage Scheme" (p. 209).

People were also incentivized to take up the package to the UK, by housing offers and financial support, and access to employment, health services, and schooling. The drive to seek educational opportunities for children was one of the most common themes in the discussions. However in many cases, this led mothers and children alone to migrate (Young 2004; Shotte 2007; McLeman 2011). This can be articulated as both a pull and a push factor, in that the education system in the island was initially severely disrupted by loss of facilities, departure of staff and by the usage of schools in the north as shelters.

The separation of family members was one of the major consequences of the migration process, as in many cases, fathers and grandparents were left behind:

"....so at one stage we had the men here who were basically involved in the reconstruction and trying to keep things going, but the partners were in England and in different parts of the Caribbean with the children. So that created another social problem, in that some of the children adapted well, but some of them, exposed to a new environment, just couldn't handle it and we heard about them getting into trouble." (Retired community services employee)

Given that many families were forced to relocate without their fathers, this lack of paternal support may have influenced the behaviour of some students (Shotte 2002). There were some accounts of poor performance in schools, reportedly as a result of 'corrupting influences' of some British school children, and/or the challenges of students trying to defend their ethnic identity (Shotte 2006). Whatever the reason for perceived, or actual behaviour change, several students clearly struggled with the challenges of adapting to a new social and cultural situation: "the seeking of autonomy and independence from parents, together with constant identity reconstruction have put extraordinary emotional strain on relocated students psyches' - a situation that has impacted negatively on their overall educational progress" (Shotte 2006, p.34). Despite better education being a driving force for emigration, there were also reports of some Montserratian parents' displeasure at some teaching standards and the perceived regression of learning (Windrass and Nunes 2003); a perception rooted perhaps in the difference in relationships between teaching and learning in different cultures (Montserrat as an interdependent culture and Britain as an independent one).

Particularly for those migrants without access to preexisting networks with friends and family in the UK, the new conditions they faced posed several challenges, 
especially in the early years of the crisis (Shotte 2007). Migrants were dispersed to several UK cities, and many were re-housed in socially-deprived neighbourhoods and hostels. They also had to cope with the challenges of acquainting themselves with unfamiliar economic, social and cultural situations. Some appear to have coped well, but others struggled severely in the early years. In particular, there were challenges of benefit delay, attributed to the difficulties of obtaining a National Insurance number (Pattullo 2000). Further, some rented accommodation also lacked furnishings, including beds. There were challenges of finding employment without references or recognised qualifications, even for those who had positions of accountability in Montserrat (Pattullo 2000). For many older people who did make the move under the assisted migration package, re-establishing life in the UK appears to have been particularly difficult:

"Depending on where they landed we got reports back that some did fare very well in terms of the organization and them learning the system, which would have been difficult for the real old persons without family members. And we just kept hearing the announcements of a number of them in those early days that they got there but what next, what is the will to live. So ....from going outside and planting your garden and harvesting your stuff to now locked up in an apartment. Granted you are getting the dole but these people are not dole people. And it's cold. These people are people who are 70 odd, 80 years of age and they got up every morning and tied out their animals and planted some food, cooked their food. Now you took them into an apartment and you say, ok, you don't have to worry you'll get your food etc - but for some it was a real shock." (Retired community services employee)

In the longer-term, the UK-based Montserrat community have maintained their cultural and emotional ties to Montserrat (Shotte 2007; Hill 2014) but there are low levels of return - only 60 people took up the return package to Montserrat when it was offered in 2003. Montserratians are unlikely to return to the island until more of the island becomes accessible, and employment and housing opportunities are comparable to the UK:

"Lots of Montserratians would think twice about going back to invest. In terms of setting up a big business [you] have got to look at population." (UK-based Montserratian)

However it is not just population numbers that seem to discourage migrants to return to Montserrat; the presentday population structure is such that there is also an anxiety that Montserratian culture has largely been lost (Greenaway 2011; Hill 2014). Further, it is also likely that long-term residency in the UK has created an intergenerational adaptability to the British way of life:
"The majority of people in the UK are settled. Some people who wouldn't have had a chance to go to university in Montserrat - they have the knowledge but not the cash - but in the UK they do. .... [The] major- ity of people make use of the opportunity. (UK-based Montserratian).

\section{Differentiated and dynamic vulnerability}

The story of Montserrat's volcanic eruptions received several pages of coverage in the second edition of $A t$ Risk, a landmark publication in the evolution of ideas around disaster risk and social dimensions of vulnerability (Wisner et al. 2004). Though most of the discussion, as elsewhere, focussed on island-wide risk factors and the overall management of the crisis, the authors did make reference to a social differentiation in how the short and medium-term consequences played out for different social groups. They begin this passage with the following words:

'Volcanoes can be seen as great levellers, potentially deadly to all life and all people, rich or poor, who are within reach of their destructive power. But in the case of Montserrat there were exceptions.' (Wisner et al 2004, p.307).

It is the story of the 'exceptions' that forms the focus of this paper. In doing so, we can question just how exceptional these 'exceptions' are in the context of volcanic risk.

Discussion of risk associated with volcanoes has generally tended to focus on immediate threats to life from exposure to lethal volcanic hazards. Such losses of life were kept numerically low in Montserrat by the successive evacuations, but 19 people were killed by pyroclastic flows on $25^{\text {th }}$ June 1997. The return of people, mostly smallholder farmers, to the flanks of the volcano contributed to this loss of life. It has been argued that, for many, a combination of the strains of shelter life, shortage of cash and the fear of losing standing crops and livestock was motivation to return (Wisner et al. 2004). This was a particular social group facing difficult living conditions in the public shelters and with high livelihood dependence on land that they could not replace in the north.

However, as with other volcanic disasters, the vast majority of people severely affected by the Montserrat eruptions were well out of the way when lethal flows swept down the valleys from Soufrière Hills. For the surviving majority it is vulnerability in terms of ongoing livelihood 
and wellbeing that becomes key, and in Montserrat social differences in underlying vulnerability become manifest in the unfolding story of crisis and response. These differences became especially heightened by the longerterm impacts of the crisis - beyond the immediate effects of the hazard events.

Critical social science research on disaster risk emphasizes the importance of pre-existing assets and resources in shaping both how seriously affected people's lives may be by hazards and how readily they may recover (Anderson and Woodrow 1998; Chhotray and Few 2012). Vulnerability to hazards is therefore inherent in antecedent conditions. The preceding section has described the difficult situation faced by long-term shelter dependents, poorer nonmigrants and assisted passage migrants in the years following the major eruptions. These groups are not discrete and there are overlaps and linkages between them that reinforced the social pattern of impact, for example, in the situation faced by older people left behind as other family members took assisted passage, and in the eventual movement of people from shelter to poor quality housing or rental accommodation.

The volcano's impacts touched everybody, and the hardship was widely distributed, as people lost their homes and businesses in the south. But many displaced residents had the financial or social means to bypass the shelters (or move rapidly from them) to alternative homes in the north or overseas, and were able to access savings, credit or assistance from personal networks to rebuild their standards of living. By contrast, many of those most vulnerable during and after the major eruptive phase came into the crisis with lower incomes, fewer economic assets and limited social networks (e.g. marginalised farmers not living in the former capital Plymouth). In terms of impacts of the crisis on these groups, relatively fewer livelihood assets constrained options for accommodation, migration and occupation. This parallels wider work on household decision-making in development studies that highlights how constrained access to livelihood assets limits the adaptive choices available to people in response to shocks and stresses (e.g. Ellis 2000; McDowell and Hess 2012). The outcome for these groups was heightened deprivation extending beyond the immediate impacts of the eruption and evacuation of the south into the medium-term.

In other words, if applying mainstream disaster management concepts, one can see that severe impacts of the hazards were experienced for these groups for several years at least into the disaster 'recovery' period. Their differential vulnerability to the volcanic hazards therefore became manifest through the unfolding of the volcanic-generated social crisis that ensued - in ways that could not simply be 'read off' from the physical effects of the ashfalls and the pyroclastic flows.
While perhaps this reflects a predictable pattern of underlying vulnerability, shaped largely by pre-existing relative poverty and/or social marginalization it is essential also to reflect on the dynamics of vulnerability, and how those patterns may have shifted during the course of the crisis (see Rigg et al. 2008 for an exploration of equivalent vulnerability dynamics following the 2004 Indian Ocean tsunami). Though we did not have the chance to collect data to verify this, it is possible that others moved into a condition of poverty and marginalization through loss of homes and businesses in the south and withdrawal of insurance cover, and through dispersion of social networks through the displacement and migration process. Hence people may have experienced impacts that subsequently undermined their pre-existing capacities to cope and manage crisis - they effectively joined the highly vulnerable group through the passage of events.

Certain crisis management decisions, actions and inactions - some of these associated with the political difficulties of working in a situation of high uncertainty were key in shaping vulnerability dynamics (see Clay et al. 1999; Wilkinson 2015 [in this volume]). Some such actions may have been unavoidable. For example, the major evacuations (and smaller, repeated ones) and the exclusion zoning led to a loss of non-fixed assets such as crops and livestock, as well as fixed assets. Inability to retrieve those assets impaired recovery. However, we have seen that the enforcement of exclusion was not entirely complete, which, on the one hand enabled some people to attempt to retrieve assets, and, on the other hand, endangered their lives.

Other aspects of crisis management which may have been handled differently also shaped shifts in vulnerability. The poor shelter conditions appear to have prompted several people to return to homes and landholdings in the exclusion zone, and thus increased their hazard exposure. Slow progress in establishing land and homes for resettlement in the north prolonged the time in which people with limited alternatives had to reside in inadequate shelter. The nature of migrant placements in the UK radically transformed the social context for the migrants, and insufficient support for families in difficult environments without ready access to social networks appears to have exacerbated emotional and behavioural problems and contributed to educational issues.

However, this situation was not necessarily permanent nor an inter-generational 'trap'. Just as people's circumstances can change negatively so they can change for the positive. The story of Montserrat's volcanic crisis is one of constant flux - physically and socially - and over the longer term, a form of recovery has set in, even though the cultural and environmental landscape in which it is doing so has been radically altered. Those who remained, moved to, and returned to Montserrat, have the chance of access 
to improved housing schemes and are seeing business and economic opportunities being rebuilt since the devastation of the south of the island. Many of the assisted migrant families who remained in the UK have experienced social mobility over time, particularly as younger members began to emerge from education into a wider job market than existed in Montserrat. Disasters can have the potential to act as moments of wider social change (Pelling and Dill 2010) though we would always argue that vulnerability analysis requires us to look beyond the aggregate to see how both impacts and recovery trajectories are socially differentiated.

\section{Conclusions}

Are volcanoes 'great levellers', or should we indeed expect their effects, like most other natural hazards, to be far from even? Evidence from Montserrat, and also from research at other volcanoes, such as Pinatubo (Crittenden et al 2003; Gaillard 2008), suggest that we should expect the latter. To be sure, the chances of surviving direct exposure to a pyroclastic flow are close to zero, whoever you may happen to be. But, the chances of coping through the ensuing disruption, of maintaining wellbeing and of recovering losses and rebuilding livelihoods are highly variable, shaped both by individual characteristics and by social structures.

Vulnerability to hazards is a complex and socially differentiated characteristic. The differentiation of effects is especially manifest over the long-term in a prolonged crisis and one involving radical disruption, as in Montserrat. Reports to date have generally discussed overall impacts and disaster management, and there is much ongoing debate about the resilience of the general island population. But we also need to look beyond the general context to ask who's impacts, who's recovery, who's resilience? Using mixed sources, the forensic work on Montserrat was an opportunity to collate the stories of the most vulnerable groups - and view how the medium/long-term impacts of the volcanic crisis on these social groups were linked to large extent with preceding socio-economic conditions.

However, it is also important to understand the dynamics of vulnerability, particularly through the course of a long-lived crisis. In an individual sense, people's lives were in flux through the duration of the crisis some lost, some gained key assets that changed the nature of their vulnerability to ongoing impacts. In a wider sense, physical events and organizational decisions and inactions actively accentuated the social differentiation of impacts, through the processes of evacuation, shelter provision, resettlement, rehabilitation and migration. Because vulnerability is shaped by so many interlocking social and environmental factors change in vulnerability is not necessarily sequenced by disaster events. However, successive hazards and the variable responses they can trigger do constitute a dynamic that on occasion can be 'game-changing'. By taking a partial view of causation here - we can see how the specific unfolding of events in Montserrat led to social outcomes (or manifestations of vulnerability) that were not entirely predictable when the emergency began.

\section{Endnotes}

${ }^{\mathrm{a}} \mathrm{SHV}+17=$ the 17 years since eruption onset (at the time of the workshop).

${ }^{\mathrm{b}}$ Triangulation refers to assessing, comparing and cross checking findings using a plurality of evidence sources, derived, for example, from diverse methods, informants, inquirers or contexts.

'Outcome-based analysis of vulnerability, or end-point analysis, considers the impacts of volcanism (in this case) on specific social groups as an indicator (or manifestation) of underlying vulnerability, and employs social science research to explain the reasons why that vulnerability exists, varies and changes.

${ }^{\mathrm{d}}$ The first Sustainable Development Plan was devised in 1997 (covering the period 1997-2002) and was developed in the 2003-2007 document. The most recent plan, published in 2010, encompasses the period 2008-2020. All documents were developed by the Ministry of Economic Development and Trade, Government of Montserrat.

'While the 'temporary' housing is widely referred to as T1-11 housing, this is actually the code of the ribbed plywood siding itself. The housing units were timber framed with a plywood wall sheeting and a corrugated steel roof.

${ }^{f}$ While exact numbers and nationalities of immigrants was unknown during this time, many interviewees reported that most immigrants originated from Santo Domingo and Guyana.

${ }^{\mathrm{g}}$ The inquest was held in November 1998, and the report published in January 1999.

\section{Abbreviations}

DfID: Department for International Development; EOC: Emergency Operations Centre; ESRC: Economic and Social Research Council; FCO: Foreign and Commonwealth Office; FORIN: Forensic Investigation of Disaster; IDNDR: International Decade for Natural Disaster Reduction; NERC: Natural Environment Research Council; SAC: Scientific Advisory Committee on Montserrat; SHV: Soufrière Hills Volcano; STREVA: Strengthening Resilience in Volcanic Areas.

\section{Competing interests}

The authors declare that they have no competing interests.

\section{Authors' contributions}

$\mathrm{AH}$ and RF both attended the STREVA forensic workshop in Montserrat and gathered focus group and key informant data. Coding and analyses were conducted by $\mathrm{AH}$ and RF. $\mathrm{AH}$ and RF drafted the manuscript. Both authors read and approved the final manuscript.

\section{Acknowledgments}

The authors wish to express their sincere gratitude to all those from Montserrat who participated with enthusiasm and interest in the forensic research process. We also acknowledge the support given by Jenni Barclay and the wider STREVA team, particularly: Paul and Liz Cole for facilitating access on Montserrat; Emily Wilkinson and Jonathan Stone for contributing to data acquisition; and Peter Simmons, Richard Herd and Jenni Barclay for 
contributing to the data coding process. The authors wish to thank Steve Sparks for an internal review of this manuscript, Victoria Sword-Daniels for helpful remarks, Chris Kilburn for editorial control, and two anonymous reviewers for comments on an earlier version of this paper. Funding for the STREVA project is provided by the NERC-ESRC Increasing Resilience to Natural Hazards Programme (grant number NE/J020052/1). Financial support for this open-access manuscript was kindly provided by the University of East Anglia.

\section{Author details}

${ }^{1}$ School of Environmental Sciences, University of East Anglia, Norwich Research Park, Norwich, Norfolk NR4 7TJ, UK. ${ }^{2}$ School of International Development, University of East Anglia, Norwich Research Park, Norwich, Norfolk NR4 7TJ, UK.

\section{Received: 18 September 2014 Accepted: 11 February 2015 Published online: 25 February 2015}

\section{References}

Anderson MB, Woodrow PJ (1998) Rising from the ashes: development strategies in times of disaster. IT Publications, London

Aspinall WP, Loughlin SC, Michael FV, Miller AD, Norton GE, Rowley KC, Sparks RSJ, Young SR (2002) The Montserrat volcano observatory: its evolution, organization, role and activities. In Druitt TH, Kokelaar BP (eds) The eruption of Soufrière Hills Volcano, Montserrat, from 1995 to 1999. Geological Society, London, Memoirs 21(1):71-91

Avery JG (2003) The aftermath of a disaster: recovery following the volcanic eruptions in Montserrat, West Indies. West Indian Med J 52:131-135

Bankoff G, Frerks G, Hilhorst D (eds) (2004) Mapping vulnerability: disasters, development and people. Earthscan, London

Burton I (2010) Forensic disaster investigations in depth: a new case study model. Environment 52(5):36-41

Chambers R (1994) The origins and practice of participatory rural appraisal. World Dev 22(7):953-969

Chhotray V, Few R (2012) Post-disaster recovery and 'ongoing' vulnerability: ten years after the super-cyclone of 1999 in Orissa, India. Glob Environ Chang 22:695-702

Clay E, Barrow C, Benson C, Dempster J, Kokelaar P, Pillai N, Seaman J (1999) An evaluation of HMG's response to the Montserrat volcanic emergency, 2 vols. Evaluation report EV635. Department for International Development, London

Crittenden KS, Lamug CB, Nelson GL (2003) Socioeconomic influences on livelihood recovery of Filipino families experiencing recurrent lahars. Philipp Sociol Rev 51:115-134

Cutter SL (1996) Vulnerability to environmental hazards. Prog Hum Geogr 20:529-539

Dibben C, Chester DK (1999) Human vulnerability in volcanic environments: the case of Furnas, Sao Miguel, Azores. J Volcanol Geotherm Res 92(1-2):133-150

Ellis F (2000) The determinants of rural livelihood diversification in developing countries. J Agric Econ 51(2):289-302

Few R (2007) Health and climatic hazards: framing social research on vulnerability, response and adaptation. Glob Environ Chang 17(2):281-295

Forbes L, Jarvis D, Potts J, Baxter PJ (2003) Volcanic ash and respiratory symptoms in children on the island of Montserrat, British West Indies. Occup Environ Med 60:207-211, doi:10.1136/oem.60.3.207

Gaillard JC (2008) Alternative paradigms of volcanic risk perception: the case of Mt Pinatubo in the Philippines. J Volcanol Geotherm Res 172(3-4):315-328

Greenaway (2011) Montserrat in England: dynamics of culture. iUniverse, Bloomington IL

Halcrow Group Limited and the Montserrat National Assessment Team (2012) Country Poverty Assessments vol. 2. Supplementary Material pp.162.

Hicks A, Barclay J, Simmons P, Loughlin S (2014) An interdisciplinary approach to volcanic risk reduction under conditions of uncertainty: a case study of Tristan da Cunha Nat. Hazards Earth Syst Sci 14:1871-1887, doi: 10.5194/ nhess-14-1871-2014

Hill $L$ (2014) Life after the volcano: the embodiment of small island memories and efforts to keep Montserratian culture alive in Preston, UK. Area 46 (2):146-153, doi: 10.1111/area.12084

Hincks T, Aspinall W, Baxter P, Searl A, Sparks R, Woo G (2006) Long term exposure to respirable volcanic ash on Montserrat: a time series simulation. Bull Volcanol 68(3):266-284

Howe T (2003) The impact of the Montserrat volcanic eruption on water and sanitation 1995-1997, and lessons learned. Prepared for the $12^{\text {th }}$ Annual
CWWA Conference, Bahamas pp. 12 www.bvsde.paho.org/bvsacd/cwwa/ howe.pdf.

Kokelaar BP (2002) Setting, chronology and consequences of the eruption of Soufrière Hills Volcano, Montserrat (1995-1999). In Druitt TH, Kokelaar BP (eds) The eruption of Soufrière Hills Volcano, Montserrat, from 1995 to 1999. Geological Society, London, Memoirs 21(1):1-43

Loughlin SC, Baxter PJ, Aspinall WP, Darroux B, Harford CL, Miller AD (2002) Eyewitness accounts of the 25 June 1997 pyroclastic flows and surges at Soufrière Hills Volcano, Montserrat, and implications for disaster mitigation. In Druitt TH, Kokelaar BP (eds) The Eruption of Soufrière Hills Volcano, Montserrat, from 1995 to 1999. Geological Society Memoir 21(1):211-230, doi:10.1144/GSL.MEM.2002.021.01.10

McDowell J, Hess J (2012) Accessing adaptation: multiple stressors on livelihoods in the Bolivian highlands under a changing climate. Glob Environ Chang 22:342-353

McLeman RA (2011) Settlement abandonment in the context of global environmental change. Glob Environ Chang 21(suppl 1):S108-\$120

Mitchell T (2001) Discussion of "Second hazards assessment and sustainable hazards mitigation: disaster recovery on Montserrat" by Rozdilsky R. Natural Hazards Review 74(2,2):64-71

Pattullo P (2000) Fire from the mountain: the tragedy of Montserrat and the betrayal of its people. Constable, London

Pelling M (2003) Disaster risk and development planning: the case for integration. Int Dev Plan Rev 25(4):i-ix

Pelling M, Dill C (2010) Disaster politics: tipping points for change in the adaptation of socio-political regimes. Prog Hum Geogr 34:21-37

Rigg J, Grundy-Warr C, Law L, Tan-Mullins M (2008) Grounding a natural disaster: Thailand and the 2004 tsunami. Asia Pacific Viewpoint 49(2):137-154

Rozdilsky JL (2001) Second hazards assessment and sustainable hazards mitigation: disaster recovery on Montserrat. Natural Hazards Review May 2001:64-71

Schipper L, Pelling M (2006) Disaster risk, climate change and international development: scope for, and challenges to, integration. Disasters 30(1):19-38

Scientific Advisory Committee on Montserrat (2013) Assessment of the hazards and risks associated with the Soufrière Hills Volcano, Montserrat. Eighteenth report of the scientific advisory committee on Montserrat Volcanic Activity. Montserrat Volcano Observatory Part II: Full Report pp. 76 www.mvo.ms/pub/ SAC_Reports/SAC18-Full.pdf.

Shotte G (2002) Education, migration and identities: relocated Montserratian secondary school students in London schools. Ph.D. thesis, Institute of Education, University of London.

Shotte G (2006) Identity, ethnicity and school experiences: relocated Montserratian students in British schools. Refuge 23(1):27-39

Shotte G (2007) Diasporic transnationalism: relocated Montserratians in the UK. Caribbean Quarterly 53(3):41-69

Skelton T (2003) Globalizing forces and natural disaster: what can be the future for the small Caribean island of Montserrat? In: Kofman E, Young G (eds) Globalization: theory and practice, 3rd edn. Continuum, London

Smith Warner International (2003) Integrated vulnerability assessment of Montserrat. Submitted to the Government of Montserrat, June 2003 pp.76.

Stair AG, Pottinger AM (2005) Disaster preparedness and management in the Caribbean: the need for psychological support. West Indian Med J 54(3):165-166

Sword-Daniels V (2011) Living with volcanic risk: the consequences of, and response to, ongoing volcanic ashfall from a social infrastructure systems perspective on Montserrat. N Z J Psychol 40(4):131-138

Sword-Daniels V, Wilson TM, Sargeant S, Rossetto T, Twigg J, Johnston DM, Loughlin SC, Cole PD (2014) Consequences of long-term volcanic activity for essential senvices in Montserrat: challenges, adaptations and resilience. In Wadge G, Robertson REA, Voight B (eds) The Eruption of Soufrière Hills Volcano, Montserrat from 2000 to 2010. Geological Society, London, Memoirs 39:471-488, doi:10.1144/M39.26

Wadge G, Robertson REA, Voight B (2014a) The eruption of Soufrière Hills Volcano, Montserrat from 2000 to 2010. Geological Society, London, Memoirs 39:pp501

Wadge G, Voight B, Sparks RSJ, Cole PD, Loughlin SC, Robertson REA (2014b) An overview of the eruption of Soufrière Hills Volcano, Montserrat form 2000 to 2010. In Wadge G, Robertson REA, Voight B (eds) The Eruption of Soufrière Hills Volcano, Montserrat from 2000 to 2010. Geological Society, London, Memoirs 39:1-40, doi: 10.1144/M39.1

Wilkinson E (2015) Beyond the volcanic crisis: co-governance of risk in Montserrat. Journal of Applied Volcanology 4(3) doi:10.1186/s13617-0140021-7. 
Windrass G, Nunes T (2003) Montserratian mothers' and English teachers' perceptions of teaching and learning. Cogn De v 18(4):555-577

Wisner B, Blaikie P, Cannon T, Davis I (2004) At risk: natural hazards, people's vulnerability and disasters, 2nd edn. Routledge, London

Young I (2004) Monserrat: post volcano reconstruction and rehabiliation-a case study. In: Proceedings of the second international conference on postdisaster reconstruction: planning for reconstruction, Coventry university UK., pp 22-23

Young SR, Sparks RSJ, Aspinall WP, Lynch LL, Miller AD, Robertson REA, Shepherd JB (1998) Overview of the eruption of Soufrière Hills Volcano, Montserrat, 18 July 1995 to December 1997. Geophys Res Lett 25(18):3389-3392

Submit your manuscript to a SpringerOpen ${ }^{\circ}$ journal and benefit from:

- Convenient online submission

- Rigorous peer review

- Immediate publication on acceptance

- Open access: articles freely available online

- High visibility within the field

- Retaining the copyright to your article

Submit your next manuscript at $>$ springeropen.com 